\title{
Metáforas de la modernidad tardía: nihilismo y «muerte de Dios» en el pensamiento nietzscheano
}

\author{
FERNANDO VERGARA HENRÍQUEZ \\ Universidad Católica del Maule (Chile) \\ fvergara@ucm.cl
}

\begin{abstract}
Resumen
El presente artículo, intenta hacerse cargo de las discusiones filosóficas en torno al anuncio nietzscheano de la «muerte de Dios» entendido éste como un evento pluricultural, teórico-práctico y teológico, que ha logrado converger y fijarse como la metáfora determinante dentro de una modernidad que opera un superabundante orden tendenciosamente universal y necesario, producido en un contexto caracterizado por un mundo «desencantado», una multiplicidad ético-moral y una insospechada capacidad técnica.
\end{abstract}

Palabras claves: modernidad, Nietzsche, nihilismo, «muerte de Dios».

\section{Metaphors of the late modernity: nibilism and «death of God» in the nietzche's thought}

\begin{abstract}
This article addresses the philosophical discussions on Nietzche's "death of God declaration», understood as a multicultural, theoretical and practical theological event. A declaration that has managed to converge and define a decisive metaphor within the modern context, a context which operates as a tendentious, necessary, universal and superabundant order in a «disenchanted», multi-ethical-moral world with unexpected technical capacity.
\end{abstract}

Key words: modernity, Nietzsche, nibilism; «death of God».

Doctor en Filosofía por la Universidad de Deusto-Bilbao (España). Profesor del Departamento de Filosofía de la Universidad Católica del Maule (Talca, Chile). Entre sus publicaciones recientes destaca "Patxi Lanceros y las fronteras reveladas de lo moderno. De la revolución a la globalización" (2009), "Patxi Lanceros y el cansancio de una modernidad onto-tecnologizada" (2009), "La apropiación de(1) sentido de la comprensión: las experiencias hermenéuticas de diálogo y comprensión a partir de Gadamer" (2008), "Gadamer y la "comprensión efectual": diálogo y tra-dicción en el horizonte de la koiné contemporánea" (2008).

El presente artículo se inscribe dentro del Proyecto de Investigación Postdoctoral que actualmente el autor lleva a cabo en el Departamento de Historia de la Filosofía, Estética y Filosofía de la Cultura de la Facultad de Filosofía de la Universidad de Barcelona (España), bajo la tutoría del Dr. Miguel Morey Farré. Proyecto titulado La modernidad revelada. Estructuración y rendimiento bermenéutico de la figuratividad en el pensamiento de Nietzssche y Gadamer, con apoyo financiero de Becas Chile-CONICYT 2009-2011, Nº 74090015. 


\section{Introducción}

Para comenzar nuestra indagación sobre las metáforas de la modernidad en el pensamiento nietzscheano, recordemos el lamento de Hölderlin de la lejanía de los dioses $^{1}$ y a Hegel y su Dios ausente en la cultura expresado en un «dolor histórico» y figurado en el «viernes santo especulativo» o «el sentimiento sobre el que se basa la religión de la época moderna, el sentimiento de que Dios mismo ha muerto» ${ }^{2}$, levantan los umbrales de las profecías racionales de la modernidad que narran el enigmático relato de la «sombra de Dios» que se alza amenazante de cubrir, a lo menos, parte de la historia racional y espiritual de occidente y marca ésta la opaca línea que separa el acontecimiento ${ }^{3}$ de la «muerte de Dios» de la conciencia que se tiene de él y sus consecuencias inaprensibles ${ }^{4}$.

Marcar estas líneas es el objetivo que nos proponemos en este artículo. Se trata de una lobreguez que alcanza nuestros tiempos de manera radical, pues denota simbolizaciones fracturadas: -lusiones, alusiones e i-lusiones de un destino costoso y trabajoso en reflexiones e inflexiones que alcanza a la misma modernidad de manera pregnante: «'Dios ha muerto', dijo Nietzsche, con una frase demasiado célebre. En el añadido: 'y nosotros lo hemos matado' se trasluce una arrogancia racionalista, se percibe el vómito -jDios le haya perdonado!- de un fanatismo iluminista» ${ }^{5}$. La modernidad ha operado una pasión que, a la vez, expresa una radical desubstancialización y desmitologización de lo

1 F. HÖlderlin: Poesía completa. Ediciones 29, Barcelona 2005, 'Pan y vino', 313323.

2 G. W. F. HeGEL: Fe y saber o la filosofía de la reflexión de la subjetividad en la totalidad de sus formas como filosofía de Kant, Jacobi y Fichte. Biblioteca Nueva, Madrid 2000, 164.

3 «Denominemos acontecimiento a cualquier hecho o ente aislable, individualizable, independientemente del orden a que pertenezca», P. LANCEROS: La herida trágica: el pensamiento simbólico tras Hölderlin, Nietzsche, Goya y Rilke, Anthropos, Barcelona 1997, 152. Nosotros aquí denominaremos como «acontecimiento» aquel suceso que forma o hace época en la existencia histórica, y por ello, no puede ser olvidado, pero que a la vez, rebasa la comprensión del sujeto.

4 F. Nietzsche: La gaya ciencia. Akal, Madrid 1988, III, \$108, 'Nuevas luchas', 147, en adelante GC: «Después de la muerte de Buda, se mostró aún durante siglos, en una cueva, su sombra - una sombra colosal y pavorosa. Dios ha muerto: pero, siendo los hombres lo que son, habrá acaso aún por espacio de milenios cuevas donde se muestre su sombra. - ¡Y nosotros -tendremos que vencer también a su sombra!» Sobre «las largas piernas» de la sombra de Zaratustra, de su cómplice compañía, de su cansancio y posterior baile. Vid. F. NIETZSCHE: Asi babló Zaratustra. Un libro para todos y para nadie. Alianza, Madrid 2004, IV, 'La sombra', 370-374, en adelante $Z$.

5 G. ColLi: Después de Nietzssche. Anagrama, Barcelona 1988, 'Vida eterna y larga vida', 73 . 
trascendental junto con una soberbia objetivación y matematización de la realidad y que, en la actualidad, modula un «desmantelamiento» de «toda interferencia colectiva en el destino individual» ${ }^{6}$.

El acontecimiento histórico de la «muerte de Dios», como aquí se presentará, es símil al crepúsculo teórico-práctico que hace de la modernidad desde sus orígenes racionalizantes hasta su agotamiento teórico actual, ya que a pesar de ser un acontecimiento silencioso de sentidos múltiples, representa la liberación del hombre de toda sujeción al transmundismo donde «el mundo suprasensible [aquel de las ideas metafísicas] ha perdido fuerza efectiva [y ya no] procura vida» ${ }^{7}$, es decir, ha dejado de ser fundamento de lo real y su reflejo, pues «si el mundo suprasensible de las ideas ha perdido toda fuerza vinculante y sobre todo toda fuerza capaz de despertar y de construir, entonces ya no queda nada a lo que el hombre pueda atenerse y por lo que pueda guiarse ${ }^{8}$.

Lo anterior, viene a significar el ensalzamiento de la tierra por sobre lo ultra-terreno, supone que el «monoteísmo» del «Dios cristiano» ha perdido su poder para fundamentar al ente y determinar al ser humano y no expresa un «ateísmo» militante ni radical frente a lo religioso, más bien, significa el politeísmo en una «divinización dionisíaca de los instantes» que expresa el fin de las narraciones de sentido y por ende, la significación venidera del nihilismo y de su sentido prometeico en la figura del superhombre anunciado por Zaratustra como el «sentido de la tierra»" en oposición a lo trascendente, al «más allá». En fin, es la exaltación de la vida sensible y la afirmación constatable de que ha ocurrido algo de alcances inaprensibles «con la verdad del mundo suprasensible y su relación con la esencia del hombre» ${ }^{10}$.

Tanto esta liberación como la exaltación aluden a que la potencia divina ya no es eficaz, no dispensa vida, actividad, movimiento, injerencia y operatividad; la metafísica - la filosofía occidental entendida casi exclusivamente como platonismo y luego teología platonizante- ha concluido y con ella las valoraciones que en ella encontraban su fuerza y fundamento, se han derrumbado:

Lo que hay que temer, lo que produce efectos más fatales que ninguna otra fatalidad, no sería el gran miedo [el gran miedo al hombre], sino la gran náusea frente al hombre; y también la gran compasión por el hombre.

6 Z. BAUman: La posmodernidady sus descontextos. Akal, Madrid 2001, 23.

7 M. Heidegger: "La frase de Nietzsche Dios ha muerto", en Caminos de bosque. Alianza, Madrid 1995, 196. El destacado es nuestro.

$8 \quad$ Ibíd., 197.

9 Z, "Prólogo de Zaratustra", §3, 36-38 y \$7, 44.

10 M. HeIDEgGer: Caminos de bosque, 199. 
Suponiendo que un día ambas se maridasen, entraría inmediatamente en el mundo de modo inevitable, algo del todo siniestro, la 'última voluntad' del hombre, su voluntad de la nada, el nihilismo ${ }^{11}$.

Podemos afirmar ahora que el dictum - y no el factum - nietzscheano de la «muerte de Dios», por una parte, es la fórmula ${ }^{12}$ del rechazo a toda la metafísica occidental como «paradigma onto-teo-lógico» que articula al «sen», al «pensamiento»y al «saber», puesto que, pensar el ser desde la razón ha consistido históricamente - especialmente a partir de la ciencia del ser aristotélica y de la idea de Bien platónica- pensar a Dios como garante y fundamento del ser e intentar establecer un conocimiento sobre ellos. Por otra parte, dibuja la distancia respecto a la moral judeocristiana, pues la idea de bien, desde Platón, está ligada a la existencia de Dios, ya sea como fundamento en el pensamiento cristiano, o bien, como postulado en el pensamiento kantiano.

\section{La grieta abierta por la «muerte de Dios»: el nihilismo como deshumanización}

La «muerte de Dios» realiza tanto una función arqueológica como otra genealógica al desenmascarar las utilidades que subyacen en la genealogía de los criterios morales: las virtudes cristianas emanan de la «VOz del rebaño en nosotros», que siendo incapaz de crear valores superiores, se autodesprecian en sus fracasos y se someten a instintos gregarios y antinaturales; asimismo, desenmascara el enunciado de una nueva antropología: el «superhombre», aquel que asume hasta las últimas consecuencias el prescindir de Dios, aquel hombre que vive para la tierra, que da un eterno y alegre sí a esta vida tal como es; creador de valores, capaz de no quedarse en la nada que ha desencadenado la ausencia de Dios, sino que se erige como articulador de la transvaloración de los

11 F. NiETzSCHE: La genealogía de la moral. Un escrito polémico. Alianza, Madrid 1994, III, 14, 142, en adelante $G M$.

12 Formulación que va desde lo dramático hasta lo salvífico, desde lo íntimo hasta la ciencia física, desde la unidad de sentido hasta la fragmentación, desde lo teológico hasta lo político. Vid. G. DeLEUZE: Nietzssche y la filosofía. Anagrama, Barcelona 1994, 214-219. Además tal formulación contiene y expresa un género literario "parabólico», incluso «kerigmático», que pone en escenas a personajes, a la vez, determinados e indeterminados con el fin de que los oyentes de la parábola puedan identificarse con algunos de ellos y así poder desentrañar su significación a partir de diversas lecturas e interpretaciones. Cfr. E. BISER: Nietzssche y la destrucción de la conciencia cristiana. Sígueme, Salamanca 1974. 
valores y superador del nihilismo cristiano que platónicamente había situado el centro de gravedad de la vida humana en el «más allá»:

Lo que narro es la historia de los próximos siglos. Describo lo que viene, lo que no puede venir de otra manera: el advenimiento del nibilismo. Esta historia puede ser ya narrada: pues la necesidad misma está aquí en marcha. Este futuro habla ya a través de un centenar de signos, este destino se anuncia por todas partes; para esta música del porvenir están aguzados ya todos los oídos. Ya, desde hace mucho tiempo, con una tensión torturante que crece de decenio en decenio, toda nuestra cultura europea se mueve, como hacia una catástrofe: inquieta, violenta, precipitada: como una corriente que quiere llegar al final, que ya no recapacita, que tiene miedo de recapacitar ${ }^{13}$.

La historia y su narración, los polos de «muerte de Dios» y de «superhombre», resultan los ejes de un despliegue errático tomado por la historia, de un «nihilismo» que se presenta, a su vez, en tres coordenadas que vienen a significar, de una manera provisional, la orientación al interior de un proceso de contornos difusos, las coordenadas tanto de límite $^{14}$ como desafío $^{15}$ y síntoma ${ }^{16}$ : coordenadas que puntualizan el derrumbe histórico de la potencia de los conceptos y valores que la tradición tenía como normativos y explicativos para la existencia humana; asimismo, supone el descrédito para proponer una finalidad, incorporar un orden $y$, por tanto, aportar un sentido -que en el cristianismo, en la moral, en la filosofía se encontraban establecidos con el carácter de leyes o verdades absolutas- y finalmente, pierde su validez como fuerza normativa e imperativa:

El nihilismo hace ahora su aparición no porque el displacer ante la existencia sea mayor que antes, sino porque se ha llegado en general a ser desconfiado con respecto a un 'sentido' en el mal e incluso en la existencia. Una sola interpretación sucumbió; pero, por el hecho de haber pasado por

13 F. NiETZSCHE: Fragmentos póstumos 1881-1888. Norma, Santafé 1992, noviembre 1887-marzo 1888, §2, 68-69.

14 Límite para un mundo en el que Nietzsche «no ha concebido el proyecto de matar a Dios, sino que lo ha encontrado muerto en el alma de su época», A. CAMUs: El hombre rebelde. Losada, Buenos Aires 2004, 67.

15 Cfr. R. Ávila: El desafio del nibilismo. La reflexión metafísica como piedad del pensar. Trotta, Madrid 2005.

16 «No se ha comprendido lo que, sin embargo, es palpable: que el pesimismo no es un problema, sino un síntoma, que la cuestión de si el no-ser es mejor que el ser es ya una enfermedad, un declinar, una idiosincrasia... El movimiento pesimista no es más que la expresión de una decadencia fisiológica». F. NIETZSCHE: El nibilismo: escritos póstumos. Península, Barcelona 2002, 17[8], 171. El nihilismo es una extraña fórmula que incluye relativismo e intolerancia, desenfreno y apatía, adhesión y temor. 
ser la interpretación, parece como si no hubiese ningún sentido en la existencia, como si todo fuese en vano.

Nihilismo: falta la finalidad; falta la respuesta al ‘¿para qué?’ ¿Qué significa el nihilismo? -que los valores supremos se desvalorizan.

El nihilismo es ambiguo.

A) Nihilismo como signo del poder incrementado del espíritu: en cuanto nibilismo activo.

El nihilismo puede ser un signo de fortaleza: la fuerza del espíritu puede haber crecido de tal manera que sus finalidades preexistentes ('convicciones', artículos de fe) son inapropiadas (...) Su máximun de fuerza relativa lo alcanza como fuerza de destrucción: como nihilismo activo. Su contrario sería el nihilismo cansado que ya no ataca: su forma más famosa, el budismo: en cuanto nihilismo pasivo.

B) Nihilismo como ocaso y regresión del poder del espíritu: el nibilismo pasivo como un signo de debilidad: la fuerza del espíritu puede estar fatigada, agotada, de forma que las metas y los valores hasta ahora existentes resultan inadecuados y ya no encuentran ningún crédito - (...) que todo lo que reconforta, sana, calma, anestesia, aparece en primer plano bajo diversos disfraces religiosos, o morales, o políticos, o estéticos, etc. ${ }^{17}$.

El nihilismo es la recogida mirada hacia abajo, hacia el desmoronamiento de todas las creencias corriendo el riesgo de caer con ellas. Para Nietzsche, la «historia debe, ella misma, resolver el problema de la historia, el saber debe volver el propio aguijón contra sí mismo» ${ }^{18}, \mathrm{y}$ como tal es la manifestación de procesos humanos, de presencias regulares que hablan de ella, a veces constantes, otras veces inadvertidas y como tal, el nihilismo se nos muestra como efecto, como consecuencia de la causa del cristianismo y de su práctica en la sociedad, resultado necesario de una forma impuesta de valoración y de una ordenación teórico-práctica como morada interpretativa o hermenéutica del nihilismo - la metafísica-, elevada a única interpretación del valor de la existencia humana, que operada por el dualismo platónico deshonra el devenir heracliteano y levanta dogmáticamente una estructura metafísicomoral nociva para el desarrollo integral y creativo de la vida, al «considerar feo y malo al mundo ha vuelto feo y malo al mundo» ${ }^{19}$.

En efecto, la teoría platónica de la realidad escindida entre mundo aparente y trascendente del ser y del valor, que considera a éste último como el «mundo verdadero», popularizado por el cristianismo -que produce una profunda dicotomía en el ser, ahora fracturado como

17 F. NiETZSCHE: Fragmentos póstumos 1881-1888, otoño 1887, 45-46.

18 F. NiETZSCHE: Sobre la utilidad y los perjuicios de la historia para la vida. EDAF, Buenos Aires 2000, \$8, 119.

19 GC, III, \$130, “Una decisión peligrosa”, 165. 
«metafísica del verdugo» ${ }^{20}$-, correspondió a la falta de valor de unos hombres que incapaces de afrontar la vida en su sentido trágico, imaginaron un mundo y una vida mejor más allá de ésta: el «mundo verdadero» no es más que una fábula generada por una «voluntad de poder» determinada a partir de la manipulación de conceptos en absolutización teórica:

(...) la metafísica y la moral platón-cristiana han sido el subsuelo para un determinado modo de sobrevivir. Por ejemplo, la moral cristiana, al conferir al hombre un valor absoluto como hijo de Dios, contrarrestaba la insignificancia de éste y su naturaleza contingente en el flojo aniquilador del devenir y del desaparecer. También otorga al mundo un carácter de perfección como creación divina a pesar del mal. Y hace creíble la posibilidad de un conocimiento de verdades absolutas ${ }^{21}$.

La metafísica y la moral cristianas fundan una cultura, que para Nietzsche deriva en una cultura enferma como producto de un hombre enfermo y, como tal, se manifiesta ahora con toda crudeza en su momento terminal. Esa estructura metafísica de la realidad o teoría abstracta de la realidad material, fue el resultado de una larga historia de valoración negativa de la $\mathrm{Vida}^{22}$ - que es esencialmente apropiación, atención, conquista, exploración, imposición de formas propias, «voluntad de poder»- que muestra su inconsistencia y carácter decadente cuando al final del proceso de desarrollo de su dinámica interna desemboca en la «muerte de Dios», en la «nada», en el «nihilismo». La hermenéutica metafísico-cristiana palidece las fuerzas vitales en tanto que negación valorativa articulada en una moral de la autonegación al hacer entrar en crisis los binomios «materialidad sensible» e «inmaterialidad suprasensible», entre «materialidad cambiante» e «inmaterialidad invariable y eterna»:

Los valores superiores, a cuyo servicio debía vivir el hombre, especialmente cuando disponían de él de manera dura y costosa, estos valores sociales se constituyeron con el fin de fortalecerle, como si fueran mandamientos de Dios, como 'realidad', como 'verdadero' mundo, como esperanza y mundo futuro, se construyeron sobre los hombres, ahora que se hace claro el mezquino origen de estos valores, nos parece que el

20 F. NieTzSCHE: Crepúsculo de los ídolos o cómo se filosofa a martillazos. Alianza, Madrid 1994, "Los cuatro grandes errores", \$7, 69, en adelante CI.

21 D. SÁnCHEZ MECA: El nibilismo. Perspectivas sobre la historia espiritual de Europa. Síntesis, Madrid 2004, 106.

22 «La vida acaba donde comienza el "reino de Dios"», CI, "La moral como contranaturaleza", $₫ 4,57$. 
universo se desvaloriza, 'pierde su sentido'; pero éste es solamente un estado de transición ${ }^{23}$.

No es difícil suponer, entonces, que la «forma en que se han interpretado hasta ahora los valores de la existencia» ${ }^{24}$ cobre la figura del nihilismo:

¿Qué significa nihilismo? Que los valores supremos han perdido su crédito. Falta el fin; falta la contestación al porque 25 .

Se trata de la falta de meta, del horizonte, del necesario fluir de este mundo como conato de interpretación y de comprensión. El nihilismo es un «movimiento histórico [que] mueve la historia a la manera de un proceso fundamental, apenas conocido, del destino de los pueblos occidentales (...) no es una manifestación histórica entre otras, no es sólo una corriente espiritual que junto a otras, junto al cristianismo, el humanismo y la ilustración, también aparezca dentro de la historia occidental» ${ }^{26}$.

El nihilismo no hace referencia a nuestro presente ni a nuestro futuro, sino más bien, a nuestro pasado-siempre-presente ${ }^{27}$, a aquel marco de valores y sentidos heredados de la tradición griega platónica y judeo-cristiana como configuradores del modo occidental de modernidad. Surge la imagen de un cristianismo que carga con el «erron» de haber dejado entrar en el mundo la enfermedad de la «decadencia» a través de la compasión y el resentimiento, pero además, el convertirse en una suerte de crisol de todas las enfermedades arrastradas desde el mundo antiguo; el haber reducido a los individuos a rebaño que encontraba su afirmación (espíritu de venganza, resentimiento, mala conciencia, ideal ascético) en su negación vital, más aún, hacerlos partícipes de la concatenación histórica de acontecimientos de creación, disolución y recreación de sentido y valores contrarios a la naturaleza humana.

En el Crepúsculo de los idolos o cómo se filosofa a martillazos, Nietzsche presenta la historia del errático nihilismo platonizante y su saludable salida en seis fases:

\footnotetext{
23 F. NiETZSCHE: La voluntad de poderío. EDAF, Madrid 1981, \$7, 34.

24 Ibíd., $₫ 1,33$.

25 Ibíd., $\$ 2,33$.

26 M. HeIDEgGER: Caminos de bosque, 198.

27 Vid. F. Vergara: "Modernidad y nihilismo", en A. OrTIZ-OsÉs y P. LANCEROS (dirs.), Diccionario de la existencia. Asuntos relevantes de la vida bumana. AnthroposCRIM/UNAM, Barcelona 2006, 381-386.
} 
1. El mundo verdadero, asequible al sabio, al piadoso, al virtuoso, -él vive en ese mundo, es ese mundo. (La forma más antigua de la Idea, relativamente inteligente, simple, convincente. Trascripción de la tesis 'yo, Platón, soy la verdad'). 2. El mundo verdadero, inasequible por ahora, pero prometido al sabio, al piadoso, al virtuoso ('al pecador que hace penitencia'). (Progreso de la Idea: ésta se vuelve más sutil más capciosa, más inaprensible, - se convierte en una mujer, se hace cristiana...) 3. El mundo verdadero, inasequible, indemostrable, imprometible, pero, ya en cuanto pensado, un consuelo, una obligación, un imperativo. (En el fondo, el viejo sol, pero visto a través de la niebla y el escepticismo; la Idea, sublimizada, pálida, nórdica, königsberguense). 4. El mundo verdadero -¿inasequible? En todo caso, inalcanzado. Y en cuanto inalcanzado, también desconocido. Por consiguiente, tampoco consolador, redentor, obligante: ¿a qué podría obligarnos algo desconocido?... (Mañana gris. Primer bostezo de la razón. Canto del gallo del positivismo). 5. El 'mundo verdadero' -una Idea que ya no sirve para nada, que ya ni siquiera obliga - una Idea que se ha vuelto inútil, superflua, por consiguiente una Idea refutada: jeliminémosla! (Día claro; desayuno; retorno del bon sens [buen sentido] y de la jovialidad; rubor avergonzado de Platón; ruido endiablado de todos los espíritus libres). 6. Hemos eliminado el mundo verdadero: ¿qué mundo ha quedado?, ¿acaso el aparente?... ¡No!, ¡al eliminar el mundo verdadero hemos eliminado también el aparente! (Mediodía; instante de la sombra más corta; fin del error más largo; punto culminante de la humanidad; INCIPIT ZARATHUSTRA) ${ }^{28}$.

La primera fase, que personifica claramente al pensamiento platónico, presenta la existencia de un mundo verdadero, suprasensible, pero que, sin embargo, aún no se ha cristalizado en una entidad enteramente «ideal», sino que tan sólo alcanzable, entendible para algunos sabios. En la segunda fase del nihilismo platonizante, se abre la brecha, la fractura en el mundo en su división sensible-suprasensible, inmanencia-trascendencia, mundo que en cuanto promesa se convierte en inalcanzable incluso para los sabios, y para el pueblo: ahora es el cristianismo como platonismo popular en cuanto promesa del «más allá». Una tercera fase, representa al pensamiento kantiano, en el sentido en que el mundo verdadero se excluye de la experiencia y ha sido declarado indemostrable para la razón teórica, pero queda un consuelo: el concepto enflaquecido atado al imperativo moral universal. La cuarta fase, representa el escepticismo e incredulidad respecto a la metafísica que sigue al kantismo y al idealismo, identificada con el positivismo. Luego de la declaración kantiana de que el mundo verdadero es incognoscible, no se deduce que haya sido superado, sino que es irrelevante desde el

28 CI, "Cómo el 'mundo verdadero' acabó convirtiéndose en fábula", 51-52.

VERITAS, No 22 (Marzo 2010) 
punto de vista moral-religioso. En las fases que siguen, Nietzsche las reserva para presentar su perspectiva filosófica: la abolición del «mundo verdadero» incluyendo en su caída al mundo aparente, pero no con la intención de caer en la nada, sino de superar la dicotomía ontológica introducida por el platonismo, abriendo una vía alternativa para una nueva concepción de lo sensible y su relación con lo no sensible que nos haga salir del horizonte platónico y de sus categorías metafísicas de «verdad», «unidad», «universalidad», etc. y ampliar el horizonte hacia la Vida. La decadencia obstaculiza aquellos instintos que tienden a la conservación y a la elevación del valor de la vida, tanto multiplicador de la miseria de los sentimientos como conservador de todo lo miserable; la compasión, el resentimiento, el ascetismo, persuaden a entregarse a la «nada», al «más allá», lugar que para Nietzsche no hay «nada». Más allá de lo real hay «nada»y «no mundo», o al menos $e l$ «mundo ideal».

El nihilismo, tal como lo entiende Nietzsche, es la nadificación de una manera de hacer mundo, de cómo se ha escrito y se ha hecho legible (interpretable). En este sentido, como producto de los acontecimientos históricos, el nihilismo es un tránsito propio de nuestra cultura, es la manifestación del cansancio del espíritu de occidente que agotado ya de sostener el «mundo verdadero», se torna nihilista al descubrir la mentira metafísica y el sinsentido de los valores morales que en ella se fundamentaban: Dios como máscara de la nada y el sujeto como máscara de la razón moderna.

El sujeto pierde la confianza en los criterios con los que había guiado su existencia: la verdad se ha mostrado como el error más profundo y los valores han perdido su estimación, desdibujando el horizonte de «sentido». Un terrible vacío paralizante se instala en la conciencia porque sólo queda la tierra, este mundo terreno, desprestigiado, incluso despreciado por veinticinco siglos de plato-cristianismoracionalista. Ha irrumpido «la forma más extrema de nihilismo: ¡la nada (la 'ausencia de sentido') eternamente! ${ }^{29}$.

El sujeto moderno, embriagado por la autonomía que produce la liberación de la moral cristiana y de sus prolongaciones disciplinadoras en la cultura tras la «muerte de Dios», deberá prolongar esta ruptura hasta liberarse de todo relato que le determine externamente, debiendo adquirir mil formas diferentes, como Proteo ${ }^{30}$. La cultura moderna, entregada a la promesa del poseer/poder acumulativo y del control sobre lo natural, se juega el sentido-valor de su experiencia vital, enmarcada en

\footnotetext{
29 F. NiETZSCHE: Fragmentos póstumos 1881-1888, junio 1887, 6, 34.

30 Vid. G. VATtimo: El fin de la modernidad. Nibilismo y bermenéutica en la cultura posmoderna. Gedisa, Barcelona 1996, 33-46.
} 
una suerte de hastío, aburrimiento, bostezo y tedio como «mal del siglo» XIX que se traslada al siglo XX ampliando el socavamiento de la existencia moderna. El nihilismo co-implica la «muerte de Dios», de todo supravalor y su consecuente superación, como también sepultar a ambos sin inmolarse en el intento ni desidentizarse. De este modo, la caída de la interpretación cristiana abre, a su vez, la posibilidad de superar toda estructura simbólica como también las lógicas de poder que conformen y determinen a la subjetividad. Por tanto, esta ruptura también exige a su artífice soportar el dolor y el cansancio, la responsabilidad y la satisfacción, el abandono, el pánico y el orgullo: el abismo, pero con ojos de águila, «el que aferra el abismo con garras de águila: ése tiene valon» ${ }^{31}$.

A este proceso de extravío del sentido-valor, se le ha llamado «nihilismo» como una experiencia típicamente moderna de ausencia de sentido para el existir humano, cuyo eje es el acontecimiento metahistórico de «muerte de Dios», aquel «espacio imposible [...] el ámbito de lo trágico moderno, con plena conciencia del riesgo que supone habitar el abismo de lo trágico en ausencia de cualquier referente real o imaginario (...) se disipa y se aniquila; sobreviene el nibilismo» ${ }^{32}$ :

Para Nietzsche es claro que la figura de Dios mantenía la homogeneidad del edificio metafísico-teológico vigente en el período más prolongado de la filosofía occidental, en cuanto aparece como la síntesis hipostática de las ideas de unidad, identidad y totalidad. El sistema simbólico ofrece legitimidad, justificación y sentido a cada uno de los ámbitos de la acción humana: cultural, económico, político, moral..., hasta el punto que la vida del hombre, tanto individual como socialmente considerada, precisa en cada uno de sus momentos de la eficacia simbólica del paradigma metafísico: los criterios de la vida privada, los límites de la creación artística, los ámbitos de la investigación teórica, las pautas de la acción política..., se hallan horizontalmente vinculados entre sí y verticalmente referidos a Dios como instancia suprema de decisión, legitimidad, sentido y valor ${ }^{33}$.

El relato y la promesa decimonónicos judeo-cristiano de la acción de Dios en el mundo - tanto su elevación a paradigma cosmovisional y simbólico como su consecuente derrumbamiento-, es uno de los quicios filosóficos fundamentales, pues su aventura dramática y su patrón dogmático resultan una explosiva advertencia de la caída de los

\footnotetext{
$31 \quad$ Z, IV, "Del hombre superior", 392.

32 P. LANCERos: "Nihilismo", en A. OrTIZ-OSÉS y P. LANCEROS (dirs.): Diccionario de la existencia. Asuntos relevantes de la vida bumana, 392.

33 P. LANCEROS: La herida trágica: el pensamiento simbólico tras Hölderlin, Nietəssche, Goya y Rilke, 183.
} 
metarrelatos fundantes de la cultura occidental y no el toque que comunica la llegada del ateísmo, sino lo que desaparece es la «idea monoteísta» de Dios con todo lo que ella supone y garantiza:

Dios muere en la medida en que el saber ya no tiene necesidad de llegar a las causas últimas, en que el hombre no necesita ya creerse con un alma inmortal. Dios muere porque se lo debe negar en nombre del mismo imperativo de verdad que siempre se presentó como su ley, y con esto pierde también sentido el imperativo de la verdad y, en última instancia, esto ocurre porque las condiciones de existencia son ahora menos violentas y, por lo tanto y sobre todo, menos patéticas ${ }^{34}$.

\section{Sentidos de la «muerte de Dios» como metáforas modernas}

La dirección de las aristas del acontecimiento de la «muerte de Dios» se pueden visualizar como sigue: «no es, pues, ni un simple hecho interior, ni una peripecia de orden filosófico ni parafernalia conceptual ni menos a una suerte de rito religioso, sino una modalidad ingresada al mundo que ha tomado forma en la historia de una civilización y que, como tal, concierne a todo hombre que participe (sin haber medido su alcance) en la originalidad de esta historia» ${ }^{35}$. Como tampoco el "'descubrimiento" de una estructura objetiva del mundo [sino] un acontecimiento histórico global del que, según Nietzsche, somos simultáneamente testigos y protagonistas» ${ }^{36}$.

El fundamento-razón encarnado en Dios pierde su potencia, su fortaleza y eficacia, debido al cierre de interpretaciones en una sola posibilidad de afirmación del Dios monoteísta del cristianismo y su creencia «monótono teísta» ${ }^{37}$, el resultado de ciertos principios ordenadores del mundo inteligible que configuran una teología y una suerte de renuncia al devenir terrenal; además simboliza el fundamento del sistema metafísico como idea que explica todo lo que se ordena jerárquicamente, la realidad frente al engañoso devenir:

\footnotetext{
34 G. Vattimo: Las aventuras de la diferencia. Pensar después de Nietzsche y Heidegger. Península, Barcelona 1990, 27.

35 P. VALADIER: Nietzsche y la crítica del cristianismo. Cristiandad, Madrid 1982, 453.

36 G. VAtтimo: Nibilismo y emancipación. Ética, politica, derecho. Paidós, Barcelona 2004, 72 .

37 F. NiETZSCHE: El anticristo. Maldición contra el cristianismo. Alianza, Madrid 1993, $\$ 19,44$. En otro lugar, Nietzsche se refiere en los siguientes términos: «iSer filósofo, ser momia, representar el monótono-teísmo con una mímica de sepulturero», CI, "La 'razón' en la filosofía", $\$ 1,46$.
} 
Nietzsche [...] con el anuncio de que Dios ha muerto, es decir, que la estructura fuerte de la metafísica -archai, Gründe, evidencias iniciales y destinos últimos- sólo eran formas de garantía en épocas en las que la técnica y la organización social aún no nos habían vuelto capaces, como sucede ahora, de vivir en un horizonte más abierto, menos "mágicamente" garantizado. Los conceptos rectores de la metafísica —así como la idea de una totalidad del mundo, de un sentido unitario de la historia, de un sujeto autocentrado, eventualmente capaz de apropiarse de ellos- se revelan como medios de disciplinamiento y garantía ya no necesarios en el cuadro de las actuales capacidades de disposición de la técnica ${ }^{38}$.

Los acontecimientos de nihilismo, «muerte de Dios» y descentramiento del «logos divinizado» como referencia discursiva de la verdad y del consecuente desalojo de las presencias en el ámbito metafísico, resultan ser el santo y seña de la postmodernidad, entendiendo por el prefijo -post como una «declinación» o un «deslizamiento», es decir, como la metáfora de legibilidad o conceptuabilidad de su crisis.

Según Vattimo, los cánones de la hermenéutica ${ }^{39}$ encuentran su reconocimiento de mecanismo, su seña identitaria en tanto que «pensamiento de la época del final de la metafísica» ${ }^{40}$ análoga a la época de la «muerte de Dios»y, como se ha querido presentar, al tránsito a la postmodernidad:

El anuncio de la muerte de Dios es realmente un anuncio: o, en nuestros términos, la anotación de un curso de eventos en que nos hallamos involucrados, que describimos objetivamente sino que interpretamos arriesgadamente como concluyéndose con el reconocimiento de que Dios ya no es necesario. La complejidad hermenéutica de todo ello estriba en el hecho de que Dios ya no es necesario, se revela como una mentira superflua (mentira, precisamente, sólo en cuanto superflua) a causa de las transformaciones que, en nuestra existencia individual y social, han sido

\footnotetext{
38 G. Vattimo y P. A. RovatTi: El pensamiento débil. Cátedra, Madrid 2000, 26-27.

39 «Cuando hablamos de hermenéutica [es] mediante dos preceptos: a) distanciamiento del fundamento metafísico (esto es, de la filosofía de los primeros principios (...); pero también de la filosofía como consciente develamiento de las condiciones de posibilidad de la experiencia y de la ciencia (...); b) concepción del mundo como conflicto de interpretaciones. Estos dos rasgos (...) son claramente homólogos (...) con los caracteres que definen la modernidad y el proceso de modernización en la descripción clásica de Max Weber: tanto la disolución del fundacionalismo como la liberación del conflicto de las interpretaciones son correlatos, aunque no efectos mecánicos, de la pluralización de las esferas de existencia y de los sistemas de valores constatables en el mundo moderno», G. VATTIMO: Filosofía, politica, religión. Más allá del pensamiento débil. Nobel, Oviedo 1996, 50-51.

40 G. VATtimo: Ética de la interpretación. Barcelona, Paidós 1991, 215.
} 
introducidas precisamente por creer en él. Es conocido el esquema del razonamiento de Nietzsche: el Dios de la metafísica ha sido necesario para que la humanidad organizara una vida social ordenada, segura, sin verse expuesta continuamente a la amenaza de la naturaleza - combatidas victoriosamente gracias a un trabajo social jerárquicamente ordenado- y por las pulsiones internas, domadas por una moral sancionada religiosamente; pero hoy, que esta obra de aseguramiento está, aunque sea relativamente, cumplida, y vivimos en un mundo social formalmente ordenado, disponiendo de una ciencia y de una técnica que nos permiten vivir en un mundo sin el terror del hombre primitivo, Dios parece una hipótesis demasiado extrema, bárbara, excesiva; además, ese Dios que ha funcionado como principio de estabilización y aseguramiento es también el que ha prohibido siempre la mentira; por lo tanto, son sus mismos fieles, por obediencia, los que desmienten el embuste que él mismo es: son los fieles los que han asesinado a Dios ${ }^{41}$.

El acontecimiento que eclipsa el sentido llega a su clímax con la crítica ilustrada a la religión como un «valor»:

La Ilustración en relación a los presupuestos teológicos de nuestro pensamiento condujo a la destrucción del mundo suprasensible, y ello desde luego en todas sus formas de aparición: como valor supremo, como creador divino del mundo, como sustancia absoluta, como idea, como absoluto o también como sujeto que capta-produce las modernas ciencias naturales y la técnica ${ }^{42}$.

Por ello, la idea de Dios encarna el último metarrelato sostenedor del saber pre-moderno y sus proyecciones morales — desde la filosofía, la metafísica y la teología hasta las ciencias rigurosas, sociales y humanasdisciplinadoras y teo-metafísicas u onto-teológicas a una «modernidad sin tristezas» ${ }^{43}$ ni melancolías, pues la subjetividad moderna ya no siente nostalgia del viejo Dios ni tampoco adquiere neuróticas actitudes ante el «Dios muerto» ${ }^{44}$. Además, el relato fundante sobre Dios, se desdibuja en una galaxia abierta de narraciones e interpretaciones con múltiples sentidos sobre lo Absoluto, lo Infinito, lo Trascendente, lo Otro, etc.:

Sin voluntad ni conciencia, los acontecimientos se liberan en una multiplicidad sin medida, sin criterios, sin significado, sin sentido, sin valor.

\footnotetext{
$41 \quad$ Ibíd., 44.

42 M. FranK: Dios en el exilio. Lecciones sobre la nueva mitología. Akal, Madrid 2004, 19.

43 A. WeLLmer: Sobre la dialéctica de la modernidad y la postmodernidad. La crítica de la razón después de Adorno. Visor, Madrid 1993, 59.

44 G. VAtTimo: Más allá del sujeto. Nietsssche, Heidegger y la hermenéutica. Paidós, Barcelona 1992, 23.
} 
Los sustitutos posibles del Dios muerto provocan risa y el desasosiego de un Nietzsche que se sitúa a la distancia: la pérdida del horizonte vacía la propuesta de la modernidad, que celebra el deicidio sin reparar en sus consecuencias ${ }^{45}$.

Inconsciente del trastocamiento en el «orden», pero específicamente respecto al «encargado» de mantener este ordenamiento, pues la liberación del encarcelamiento de la «voluntad de poder» parece fraguarse independientemente de quién detente tal función y que el precio de tal liberación -la fe- no resulta alcanzable y de interés de pagar para el sujeto:

Presos. - Una mañana entran los presos al patio del penal; faltaba el carcelero. Unos, como de costumbre, se pusieron de inmediato al trabajo; otros se quedaron ociosos y mirando desafiantes alrededor. Entonces salió uno y dijo en alto: 'Trabajad cuanto queráis o no hagáis nada, es igual. Vuestros planes secretos han salido a la luz, el carcelero os ha estado espiando hace poco y en unos días os someterá a un juicio definitivo y espantoso. Ya le conocéis, es duro y rencoroso. Pero atended: hasta hoy no me conocíais; yo no soy lo que parezco, sino mucho más: soy el hijo del carcelero, y hago valer ante él lo que sea. Puedo salvaros, y quiero salvaros, pero que quede claro, sólo a aquellos que creáis que soy su hijo; los demás cosecharán los frutos de su incredulidad'. 'Entonces', dijo tras un silencio un preso viejo, '¿qué se te puede dar a ti de que te creamos o no? Si de verdad eres su hijo y puedes los que dices, dile algo en nuestro favor; eso sí que sería bondadoso de tu parte. ¡Pero deja a un lado toda esa palabrería de creer o no creer!' 'Y además', se metió voceando un joven, 'yo no le creo: sólo es algo que se le ha metido en la cabeza. Apuesto a que en ocho días nos encontraremos aquí igual que hoy, y a que el carcelero no sabe nada'. 'Y si se ha enterado de algo, ahora ya no se entera de nada' dijo el último de los presos, recién entrando al patio; 'el carcelero acaba de morir de repente'. '¡Vaya!', vocearon varios a la vez, ‘ivaya! ¿Y qué, señor hijo, como va lo de la herencia? Acaso ahora somos presos tuyos?' 'Ya os lo he dicho', replicó manso el aludido, 'liberaré a quien quiera que crea en mí, tan cierto como que mi padre aún vive'. Los presos no se rieron, pero se encogieron de hombros, y lo dejaron estar ${ }^{46}$.

Cuando Zaratustra baja de las montañas y encuentra a un anciano eremita - alienado por la protección materna de la espesura del bosquequien confiesa amar y alabar a Dios, se asombra diciendo:

45 P. LANCEROS: La herida trágica: el pensamiento simbólico tras Hölderlin, Nietzssche, Goya y Rilke, 162.

46 F. NIETZSCHE: El paseante y su sombra. Siruela, Madrid 2003, §84, 53-54. 
¡Será posible! ¡Este viejo santo en su bosque no ha oído todavía nada de que Dios ha muerto! $!^{47}$

Como es sabido, el acontecimiento filosófico-teológico e históricoespiritual del alejamiento, desviación y extravío del sujeto poseído por la pasión del espíritu y de la razón que raya con la locura, es anunciado en La gaya ciencia:

El hombre loco.- No habéis oído hablar de aquel hombre loco que en pleno día encendió una linterna, fue corriendo a la plaza y gritó sin cesar: '¡ Busco a Dios! ¡Busco a Dios!' - Como en aquellos momentos estaban allí reunidos muchos de los que no creían en Dios, provocó gran regocijo. ¿Es que se ha perdido?, dijo uno. ¿Es que se ha extraviado como un niño?, dijo otro. ¿O se te está escondiendo? ¿Es que nos tiene miedo? ¿Se ha embarcado?, ¿Emigrado? -así gritaron y rieron a coro. El hombre loco saltó hacia ellos y los fulminó con la mirada. ‘¿Dónde se ha ido Dios?', gritó. '¡Os lo voy a decir! ¡Lo hemos matado vosotros y yo! ¡Todos nosotros somos sus asesinos! Pero ¿cómo hemos hecho esto? ¿Cómo pudimos vaciar el mar? ¿Quién nos dio la esponja para borrar todo el horizonte? ¿Qué hicimos al desatar esta Tierra de su Sol? ¿Hacia dónde va ella ahora? ¿Adónde vamos? ¿Alejándonos de todos los soles? ¿No estamos cayendo continuamente? ¿Hacia atrás, hacia un lado, hacia adelante, hacia todos los lados? ¿Existe todavía un arriba y abajo? ¿No estamos vagando como a través de una nada infinita? ${ }^{48}$ ¿No nos roza el soplo del vacío? ¿No hace ahora más frío que antes? ¿No cae constantemente la noche, y cada vez más noche? ¿No es preciso, ahora, encender linternas en pleno día? ¿No oímos aún nada del ruido de los sepultureros que entierran a Dios? ¿o percibimos aún nada de la podredumbre divina? -también los dioses se pudren! ¡Dios ha muerto! ¡Dios sigue muerto! ¡Y nosotros lo hemos matado! ¿Cómo podemos consolarnos, asesinos de asesinos? Lo más santo y poderoso que ha habido en el mundo se ha desangrado bajo nuestros cuchillos - ¿quién nos limpia de esta sangre? ¿Con qué agua podríamos limpiarnos? ¿Qué fiestas expiatorias, qué juegos sagrados tendremos que inventar? La grandeza de este acto, ¿no es demasiado grande para nosotros? ¿No hemos de convertirnos nosotros mismos en dioses para aparecer dignos de él? Jamás ha habido acto más grande y todos los que nazcan después de nosotros pertenecerá por obra a una historia más grande que toda historia hasta ahora habida!' - Entonces se calló el

$47 \quad Z$, "Prólogo de Zaratustra", §1, 36.

48 Nietzsche en $G M$, III, 25, 178, se refiere en los siguientes términos a esta errancia específicamente conectada con el «mundo moderno» y su declinar: «A partir de Copérnico el hombre parece haber caído en un plano inclinado - rueda cada vez más rápido, alejándose del punto central - ¿hacia dónde?, ¿hacia la nada?, ¿hacia el 'boradante' sentimiento de su nada?». 
hombre loco, mirando de nuevo a sus oyentes: también éstos callaron, mirándolo extrañados. Al fin él arrojó al suelo su linterna, así que en pedazos y se apagó. 'Llego demasiado pronto', dijo pronto. Este acontecimiento tremendo está todavía en camino - no ha llegado aún hasta los oídos de los hombres. El rayo y el trueno requieren tiempo, la luz de los astros requiere tiempo, los hechos requieren tiempo, aún después de cometidos, para ser vistos y oídos ${ }^{49}$. Este acto para ellos está todavía más lejos que los astros más lejanos - iy sin embargo, han sido ellos quienes lo cometieron!' - Se cuenta que ese mismo día el hombre loco penetró en varias iglesias y en ellas entonó su requien aternam deo [descanso eterno para Dios], y cada vez que lo expulsaron y le pidieron cuentas se limitó a replicar: ‘qqué entonces son aún estas iglesias sino son las tumbas y monumentos fúnebres de Dios?'50.

La figura del «hombre loco», es la imagen del «descentramiento cosmovisional», de la «ruptura histórica»y de la «fisura de sentido». La «locura» expresa una suerte de clarividencia con que una mirada ve más allá de los acontecimientos presentes, y formula, por ello, la emotiva tragedia del eclipse de Dios y de la posibilidad de hallar sustituto y monta el trasfondo de la experiencia de la modernidad: la autonomía a través del poder humano desde la «muerte de Dios» para revelar y develar sus múltiples significaciones y alcances.

Ahora bien, cabe preguntarse entonces, ¿quién es el «hombre loco»? Nietzsche en su manuscrito original habría escrito una «Z» (Zaratustra) que luego tachó. Es, sin duda, el portavoz de Nietzsche, es un personaje que «habla pon» y «habla para», y siguiendo nuestra interpretación, consideramos que el exaltado, es el «sacerdote asceta», aquel sacerdote que ha «sufrido demasiado, por esto quiere hacer sufrir a otros» ${ }^{51}$. Además, es un conocedor del ejercicio de la fe, es decir, el «hombre loco» al momento de ser expulsado de las iglesias por entonar el requien aternam deo manifiesta un conocimiento que va más allá del manejo de los creyentes corrientes, es decir, denota un dominio de los rituales

49 «Los acontecimientos y pensamientos más grandes - y los pensamientos más grandes son los acontecimientos más grandes - son los que más se tarda en comprender: las generaciones contemporáneas de ellos no tienen la vivencia de tales acontecimientos, - viven al margen de ellos. Ocurre aquí algo parecido a lo que ocurre en el reino de los astros. La luz de los astros más lejanos es la que más tarda en llegar a los hombres; y antes de que haya llegado, el hombre niega que allí - existan astros. ‘Cuántos siglos necesita un espíritu para ser comprendido?' - éste es también un criterio de medida, con él se crean también una jerarquía y una etiqueta cuales se precisan: para el espíritu y para el astro», F. NIETZSCHE: Más allá del bien y del mal. Preludio de una filosofía del futuro. Alianza, Madrid 1993, 'Qué es aristocrático', \$285, 247.

50 GC, III, \125, "El hombre loco", 160-162.

$51 \quad Z$, II, "De los sacerdotes", 143. 
eclesiásticos básicos, pero no populares. El «grito» del hombre que busca a Dios rozando la desesperación, hace notoria la exterioridad del acontecimiento, es decir, no es una «muerte de Dios» que se produce en el interior de los hombres, sino en la imaginación religiosa, no se niega a Dios insensatamente, sino que se busca a Dios, pues su presencia está en la semioscuridad y las indicaciones que conducen a Él, resultan vagas y poco operativas: «el privilegio divino de resultar incomprensible» ${ }^{52}$, pero que envuelven enigmas de transfiguración.

La «palabra que hace pedazos» ${ }^{53}$, y la «mirada que traspasa», la «legibilidad silenciosa» de la dirección del mundo ${ }^{54}$ y de la «muerte de Dios», expresan la inminencia de la lejanía, es decir, del acontecer que aún no llega, pero que se espera: el acontecimiento introduce en el mundo el temor, la inquieta certeza de que «Dios» haya muerto, o esté muerto o que efectivamente morirá.

La alegría, la jovialidad, la soltura y la excesiva levedad que otorga la liberación por la búsqueda de justificaciones que re-estructuren la vida ahora sin los residuos del viejo Dios y situada en los debilitados contornos de la historia dibujados por la herida del acontecimiento:

Como está nuestra alegría.- El más grande de los acontecimientos recientes que 'Dios ha muerto', que la creencia en el Dios cristiano se ha desacreditado - empieza ya a proyectar sus primeras sombras sobre Europa. A los pocos, por lo menos, cuya mirada, cuya suspicacia en la mirada, es suficientemente aguda y sutil para este espectáculo, les parece que se hubiera puesto algún sol, que alguna inveterada y profunda confianza se hubiera trocado en duda: nuestro viejo mundo se les aparecerá forzosamente cada vez más vespertino, más receloso, más 'viejo'. Pero se puede decir en general: que el acontecimiento mismo es demasiado grande, demasiado remoto, demasiado apartado de la capacidad de comprensión de los muchos como para que pueda decirse que la noticia de ello ya ha llegado; y menos aún que muchos sepan lo que en efecto resultará de ello - y cuantas cosas, una vez socavada esa fe, tendrán que desmoronarse por estar fundamentadas sobre ella, adosadas a ella, trabadas con ella: por ejemplo, toda nuestra moral europea. Esa larga plenitud y sucesión de demolición, destrucción, hundimiento y cambio que ahora se avecina: ¿quién lo adivina hoy por hoy suficientemente para tener que ser el predicador y pregonero de esta pavorosa lógica de terror, el profeta de un ensombrecimiento y eclipse tal como probablemente jamás lo ha presenciado la tierra?... Hasta nosotros, descifradores natos, de enigmas que esperamos, por así decirlo, en las montañas colocados entre el hoy y el

52 F. Nietzsche: Sobre la utilidady los perjuicios de la historia para la vida, V, §575, 279.

53 Z, II, "La más silenciosa de todas las horas", 218.

54 Ibíd., 219. 
mañana y encajonados en la contradicción entre el hoy y el mañana, nosotros, primogénitos y prematuros del siglo futuro, que en rigor debiéramos ya percibir las sombras que no tardarán en volver a Europa: ¿cómo se explica que hasta nosotros aguardemos su advenimiento sin interés por este ensombrecimiento, sobre todo sin preocupación ni temor por nosotros mismos? Será que nos hallamos todavía demasiado sujetos a las consecuencias inmediatas, sus consecuencias para nosotros no son, contrariamente a lo que pudiera acaso suponerse, en manera alguna tristes y ensombrecedoras, sino muy al contrario como una especie nueva, difícil de definir, de luz, ventura, alivio, alegría, aliento, aurora... En efecto, los filósofos y 'espíritus libres', al enterarnos de que 'ha muerto el viejo Dios', nos sentimos como iluminados por una aurora nueva; con el corazón henchido de gratitud, maravilla, presentimiento y expectación - por fin el horizonte se nos aparece otra vez libre, aunque no esté aclarado, por fin nuestra naves pueden otra vez zarpar, desafiando cualquier peligro, toda aventura del cognoscente está otra vez permitida, el mar, nuestro mar, está otra vez abierto, tal vez no haya habido jamás mar tan abierto5.

La visión nietzscheana de la «muerte de Dios» tiene una doble vertiente de significación. Por un parte, tiene que ver con el descrédito de la creencia judeo-cristiana occidental, que ha devenido descreíble, se ha revelado nihilista y radicalmente absolutista en lo teórico. ¿Cuál es esa creencia? Es la tesis introducida por Platón del «mundo verdadero» que versa «Dios es la verdad, y la verdad es divina» en el cristianismo y que se convierte en un eje teórico-conceptual, que posteriormente en Kant se ve transformado el «mundo verdadero» en «un orden moral del mundo trascendente». Por otra parte, la declaración mortuoria de Dios supone varias otras muertes y exigencias que cargarán los hombros del «nuevo hombre en tanto que idealı:

55 GC, V, \$343, “Como está nuestra alegría”, 253-254; «iHemos dejado la tierra firme y nos hemos embarcado! ¡Hemos destruido el puente tras nosotros - más aún, hemos destruido la tierra tras nosotros! Ahora, barquita, ¡cuidado! A tu lado está el océano, es verdad que no siempre brama y que a veces se explaya cual seda y oro y ensueño de bondad. Pero horas llegarán en que te darás cuenta de que es infinito y que nada hay tan pavoroso como la infinitud. ¡Ay del pobre pájaro que se ha sentido libre y ahora choca contra las paredes de esa jaula! ¡Ay de ti, cuando te asalte la añoranza de la tierra firme, como si allí hubiese habido más libertad - pero no hay más “tierra”!», GC, III, \$124, "En el horizonte del infinito", 160. Sobre la misma metáfora, Vid. GC, IV, \279, "Amistad de estrellas", 205-206; GC, IV, \283, "La fe en sí mismo”, 209; GC, IV, \289, “iA las naves!", 211-212; GC, V, \371, "Nosotros los incomprensibles”, 299; GC, V, \374, "Nuestro nuevo infinito”, 302-303; GC, V, \$382, “¿La gran salud?”, 311-313 y GC, Apéndice, "Hacia nuevos mares", 323-324. 
(...) la muerte de un sujeto que se autodefine como criatura, efecto o analogía de un principio que lo trasciende desde un comienzo; la muerte de la metafísica, entendida como perspectiva que establece la distinción categórica entre conocimiento verdadero y falso, entre lo esencial y lo aparente, entre el sujeto y el mundo, y entre pensamiento y fenómeno; la muerte del principio que garantiza la certeza y la posibilidad de la unidad interna en el sujeto, llámese ese principio Razón o conciencia; la muerte de la teleología en la historia (es decir, de la historia como marcha ascendente hacia un orden superior) y, con ello, del principio que permite derivar hacia el futuro la promesa de una redención individual en un reencuentro universal; la muerte del mito moderno del progresivo dominio de la acción personal sobre las condiciones externas que inciden en su desarrollo; y la muerte de las cosmovisiones estables, de la temporalidad ordenada, de todo centro en torno al cual sea posible articular nuestras ideas; en fin, la muerte de la certeza y autoconfianza del yo ${ }^{56}$.

En definitiva, resulta ser una perspectiva exultante, destinal y superadora de la autónoma condición alcanzada por la modernidad:

A todos esos pájaros atrevidos que vuelan hacia espacios lejanos les llegará un momento en el que no podrán avanzar más y habrán de posarse en un mástil o en un pelado arrecife, sintiéndose felices por haber dado con tan miserable cobijo. Pero ¿cabe concluir de aquí que no queda ante ellos un espacio libre e infinito y que han volado todo lo que podían volar?

Sin embargo, todos nuestros grandes iniciadores y precursores acabaron deteniéndose, y cuando el cansancio se detiene no adopta actitudes nobles ni graciosas. Lo mismo nos sucederá a ti y a mí. ¡Otros pájaros volaron más lejos! Este pensamiento, esta fe nos anima, se echa a volar. Compite con ellos, vuela cada vez más lejos y más alto, se lanza directamente por los aires como una flecha, por encima de nuestras impotentes cabezas, y desde lo alto del cielo ve en las lejanías del espacio bandadas de pájaros mucho más poderosos, que se lanzaron en nuestra misma dirección, allí donde no hay más que mar y mar. ¿Dónde queremos ir? ¿Queremos atravesar el mar? ¿Adónde nos arrastra esta pasión poderosa, que supera a toda otra pasión? ¿A qué viene ese vuelo desesperado hacia el punto donde hasta ahora todos los soles han declinado y se han extinguido? Puede que un día se diga de nosotros que echamos a navegar hacia el oeste esperando llegar a unas Indias desconocidas, pero que nuestro destino era naufragar en el infinito. O tal vez se diga más bien, hermano mío, que... ${ }^{57}$.

56 M. Hopenhayn: Después del nibilismo. De Nietzsche a Foucault. Andrés Bello, Santiago de Chile 1998, 19-20.

57 F. NIETZSCHE: Sobre la utilidady los perjuicios de la historia para la vida, V, \$575, 279. 
Pero que, sin embargo, exterioriza una contradicción inmanente al discurso secularizador de la autonomía moderna:

La muerte de Dios libera y dispersa. Coloca al sujeto entre ambivalencias cruzadas. Lo provee de autonomía pero le sustrae fundamento y continuidad. No hay un final de la historia en que confluyan sus acciones, ni un sentido que permita inscribir su vida personal en una totalidad unitaria ${ }^{58}$.

Como afirma Deleuze, la «proposición de la 'muerte de Dios', es la proposición dramática por excelencias ${ }^{59}$ que expresa la experiencia humana de autonomía como también la conciencia del nihilismo abierto por la insolencia moderna de liberación. Además de este carácter dramático, la expresión encierra «momentos», «instancias» o «versiones» del acontecimiento que cumplen una función explicativa-genealógica del mismo, pues «la proposición dramática es sintética, luego esencialmente pluralista, tipológica y diferencial» ${ }^{60}$ que deriva en la imagen trágica del mundo, en que el trans-mundo ha sido falazmente develado y que a partir de su evidencia, comienza «el amanecer de la tierra» ${ }^{61}$, el comienzo de su sentido, la reposición de su habitante y la re-valorización de la «vida».

La declaración mortuoria de Dios, se presenta en tres partes claramente distinguibles. Atendemos primeramente a un símil representado en «sol-existencia» (máxima expresión de heroísmo frente a lo trágico de la existencia) con el «asesinato-pérdida de sentido» (máxima expresión de la depotencialización de las fuerzas vitales). Comienza con la imagen de la acción del asesinato atribuyéndole al hombre la capacidad de desatar la existencia de la tierra del sol. ¿Cómo pudo provocar el descalabro y colapso del sistema solar, acto que evidentemente escapa a todo poder humano? Esta pregunta pone de relieve otras dos cuestiones: primero, que si bien Dios, tanto en las preguntas e ironías de los ateos ${ }^{62}$,

\footnotetext{
58 M. Hopenhayn: Después del nibilismo. De Nietzsche a Foucault, 20.

59 G. DELEUZE: Nietzsche y la filosofía, 214.

60 Ibíd.

61 Ibíd., 175 y ss.

62 Z, I, "De las moscas del mercado", 90-93. Veamos aquellos símbolos representacionales de la crítica nietzscheana que aplica a su época. En el mercado pululan dos tipos de personajes de características peculiares, las «moscas» y el «pueblo», los que vienen a representar a aquellos hombres que sólo tienen sentidos para los representadores que seducen a los hombres con sus movimientos de grandilocuente comedia. Frente a estos, surge la figura de un hombre cuyo hogar es la soledad, un hombre que supera el «sí» y el «no» y que no necesita afirmarse en los inventos de los comediantes, siendo capaz de afirmarse a sí mismo en la profundidad de sí mismo. Y
} 
como en la tesis de que se lo ha asesinado aparece siendo como un hombre, y segundo, que el asesinato de Dios se muestra como un hecho autónomo de Él, siendo que, al modo de la tierra respecto del sol, recibe de Él la vida y en tal sentido depende esencialmente de Él. Por eso el destino de la tierra, del hombre, es tener al sol, a Dios, como su centro y poder girar en torno a $\mathrm{E}^{63}$.

La aspiración de la tierra de autonomía respecto del sol, es un imposible, pues se descentra radicalmente la existencia humana, porque se ha dado muerte a Dios y con él ha desaparecido todo centro de referencia fundamental que da sentido y orienta, desaparece toda dirección y la tierra se precipita a un abismo en el que no existe arriba ni abajo, adelante ni atrás: se arroja hacia todos los lados y, por ende, hacia ninguno. La tierra vaga errante en un sentido tajante: no es que se mueva sin cesar de un punto a otro, puesto que no hay referencias. La errancia es radical porque se experimenta al interior del sujeto desde una nada infinita. La ausencia absoluta de sentido y la imposibilidad absoluta de encontrarlo. Es la noche que se hace más y más noche, más y más fría, precisamente por efecto de su desvinculamiento del sol. En otras palabras, la propia vida se hace más y más imposible y camina o deriva hacia su extinción. Desatado del sol (Dios), el hombre, sin dirección se siente dueño de todas las direcciones, no obstante, es incapaz de erigir una nueva y mantenerla. El tercer punto en la serie de preguntas, reitera el carácter humano de Dios asesinado, pero con una intención que pone al descubierto algo que vendrá enseguida: pregunta a los ateos si no escuchan a los sepultureros de Dios que lo entierran, si no huelen la descomposición del cadáver de Dios. Interpretamos «descomposición» como aquel proceso de desmontaje de los fundamentos iniciados por la modernidad racionalizadora.

Se inicia con una nueva serie de preguntas, orientada a los siguientes puntos: primero, que no hay consuelo posible, esto es, perdón, redención, expiación por la acción colectiva cometida. La razón es que se ha asesinado a lo más santo y poderoso, fuente y posibilidad de todo acto de penitencia en vista al perdón y consuelo, puesto que no hay sustituto de Dios: con su muerte muere todo aquello que consuela al hombre, llámese «sentido», «valon», «verdad», cuya fuente era Dios mismo. La alternativa ha quedado clara: o Dios, fuente de la vida o la

esta autoafirmación molesta al pueblo, quien siente reflejada toda su miseria en la seguridad de sí del hombre que vive en la soledad.

63 Valadier obtura esta acción de desvinculación como un resultado ateo de la propia tradición cristiana, pues la descreencia «ha desembocado en el asesinato de Dios en la conciencia de los hombres, pues les presenta un Dios que se ha vuelto no creíble», P. VALADIER: Nietzsche y la crítica del cristianismo, 455. 
Nada y la muerte. De la sangre de Dios nadie puede lavarse, sólo Dios puede lavar su sangre y Él ha muerto. Como consecuencia, el hombre ha de cargar con el desconsuelo y culpa del acontecimiento. Pero viene un segundo punto, al que ya se había hecho referencia más arriba: se pregunta si tal acto no es demasiado grande para el hombre -lo que parece ser evidente-. Pero surge una consecuencia inesperada, aunque enteramente consistente con la lógica del texto. El acto, en efecto, le quedaba al hombre demasiado grande en un sentido muy preciso: era propio sólo de un Dios. Es lo que está en el fondo de su pretensión de autonomía total al desatarse del sol, pues tal acto es irrevocable y funda una historia nueva más alta que toda historia habida hasta entonces, convirtiéndose para el hombre en un destino. En efecto, una vez que pretendió ser igual a Dios, debió asumir de manera radical tal pretensión y esto significa ser capaz de ser efectivamente autónomo, esto es, convertirse en Dios o en supra-hombre, a lo menos, en más que un hombre.

Y la fuerza de su argumento reside en que la «muerte» y «asesinato de Dios» no son hipótesis, sino descripciones de un rasgo que define a la modernidad y al mundo contemporáneo, a saber: un mundo y una cultura en el que el hombre ha hecho de su propia autonomía el supremo valor de la existencia, buscando de manera frenética el dominio de todos los ámbitos de la existencia, para así convertirse en autodependiente, en autor y señor de la vida y la historia, en ingeniero de la felicidad y garante de su alcance mediante la ciencia y la técnica como racionalidad de medios - poder- que se define por medios económicos en función del bienestar, como único fin y supremo valor. Es importante notar que la pretensión a la autonomía de todo poder superior al hombre, la aspiración a la absoluta autodependencia (lo que se ha llamado la secularización del mundo moderno fundada en el olvido de los valores supremos que parecen caducos, fuera de moda o retrógrados), es indisociable de la aspiración al poder y omnipotencia que tendría que hacer posible tal autonomía. Y se trata, por cierto, de un poder estrictamente humano, un despliegue al infinito del poder del hombre.

La imagen nietzscheana del superhombre es ambivalente; y en esta ambivalencia se esconde un drama existencial. El superhombre representa un tipo biológico más elevado, que podría ser el producto de un cultivo consciente de su propósito, pero también es un ideal para todo el que quiere adquirir poder sobre sí y cultivar y desarrollar sus virtudes; es un ideal con fuerza creadora, que sabe tocar todo el teclado de la capacidad humana de pensar, de la fantasía y de la imaginación. El superhombre realiza la imagen completa de lo posible para el hombre, y por eso el 
superhombre de Nietzsche es también respuesta a la muerte de Dios. [...] El superhombre es el hombre prometeico, que ha descubierto sus talentos teogónicos. El Dios fuera de él está muerto; pero está vivo el Dios del que sabemos que vive solamente a través del hombre y en el hombre; este Dios es un nombre para designar el poder creador del hombre ${ }^{64}$.

El hombre no aspira a ser «Dios», sino que para llegar a ser Dios, para lo cual deberá superar las consecuencias de la «muerte de Dios»: el nihilismo en su primera fase, marcado esencialmente por la ausencia y carencia dolorosa de Dios, por la nostalgia de Dios; deberá superar todo sentimiento de carencia y nostalgia de Dios, llegando a ser capaz de suprimir de su sintaxis tanto la palabra «Dios» como la palabra «Nada». Superada esta etapa, será capaz de vivir sólo en dependencia de sí mismo ${ }^{65}$. El relato del silencio tanto del «hombre loco» como de sus auditores marca esta parte del texto. De ahí que rompa su lámpara contra el suelo (el símbolo de las consecuencias de la muerte y asesinato de Dios), simplemente porque los hombres no han tenido aún la experiencia de aquello que les habla. El acto del asesinato y desvinculamiento de Dios, es simultáneo y supone asumir la búsqueda de la autodependencia, de la omnipotencia. Y ambas exigencias son un hecho que se despliega en la modernidad, sólo que el hombre aún no ha tomado conciencia de su significado, particularmente en cuanto sigue pretendiendo ser «creyente» de una ciega veneración que ahora es una sombra de Dios, vale decir, respetar valores absolutos, vivir en función de un sentido, creer en la verdad, cree en la razón, en el progreso, en la ciencia, etc.

Finalmente, se relata el afán por parte del «hombre loco» de visitar iglesias y cantar el «descanso eterno de Dios». Este punto es altamente irónico y mordaz, pero clave para sopesar el derrumbamiento personal, espiritual del «hombre loco» como expresión de identidad, de una identidad metamorfoseada y descentrada de su sitio original. Lo que se canta en las iglesias es el requiem, es decir, «Dios, dale el descanso eterno», lo que resume el sentido del texto y espíritu moderno que persigue la autonomía. Complejos cruces de significaciones nutren el sentido del

64 R. SAFRAnSKI: Nietzsche. Biografía de su pensamiento. Tusquets, Barcelona 2001, 290291.

65 «Benignos dioses! ¡Desdichado es aquel que os ignora! Su alma grosera es presa incesante de la discordia, el mundo no es para él más que tinieblas y nada sabe de cantos ni alegría», F. Hölderlin: Poesía completa, "Los dioses", 151. 
texto, como asimismo sirve para dibujar el espíritu moderno frente a su destino ${ }^{66}$.

La «muerte de Dios» es el gran acontecimiento de la indefinición, es decir, es el advenimiento de lo que no tiene tiempo, pero que ha sucedido, lo que Deleuze y Guattari se refieren con «tiempo Aiôn»al «tiempo indefinido del acontecimiento, la línea flotante que sólo conoce las velocidades y que no cesa a la vez de dividir lo que ocurre en un déjalà [ya allí] y un pas-encore-lá [no todavía allí], un demasiado tarde y un demasiado pronto simultáneos, un algo que sucederá y que a la vez acaba de suceder» ${ }^{67}$.

Lo que debe anunciar Zaratustra - junto con la tarea reveladora de compartir la doctrina del «eterno retorno de lo mismo»-, es la gran verdad que trae su boca, que no se trata de un anhelo o deseo, sino de una constatación y explicitación de un acontecimiento aterrador: Dios ha muerto y, por ello, ha muerto también el principio y garante de la cultura como se ha venido pensando. Es la «araña universal» que está en el centro de la telaraña de la razón y que supone extraer las consecuencias inmediatas y directas de la «muerte de Dios», es decir, forzar a Dios a salir de sus tradicionales refugios, que han sido la religión, la teología, la filosofía: el verbo y el lenguaje. La vieja hembra engañadora o la razón en el lenguaje:

Temo que no vamos a desembarazarnos de Dios porque continuamos creyendo en la gramática ${ }^{68}$.

La «muerte de Dios» dibuja la bifurcación en los caminos abiertos para el hombre:

¿De lo que se trata, entonces, es de alcanzar la idea de Dios, del mundo y de la redención, en lo que uno se encuentra muy cómodamente? ¿Pero no es más bien algo indiferente el resultado de la investigación precisamente para el verdadero investigador? ¿Buscamos nosotros entonces en nuestra investigación paz, tranquilidad y felicidad? No, sólo la verdad, aunque ésta fuese sumamente horrible y repulsiva. [...] Aquí se dividen los caminos del

\footnotetext{
66 Sobre las imágenes de fenómenos y/o hechos que vendrán a reemplazar los lugares que habitaba Dios. Vid. Z, II, "De los sacerdotes", 143-146; GC, IV, \$280, “Arquitectura de los cognoscentes", 206-207.

67 G. Deleuze y F. GuatTARi: Mil mesetas. Pre-Textos, Valencia 1994, 264.

$68 C I, \$ 5,49$. Además en $G M$ resalta especialmente: «deberíamos permitirnos el concebir también el origen del lenguaje como una exteriorización de poder de los que dominan: dicen 'esto es esto y aquello', imprimen a cada cosa y a cada acontecimiento el sello de un sonido y con esto se lo apropian», GM, I, 2, 32.
} 
hombre; si quieres alcanzar la paz del alma y la felicidad, entonces cree; pero si quieres ser discípulo de la verdad, entonces investiga ${ }^{69}$.

\section{Palabras finales}

Como vimos más arriba, la noticia de que «Dios ha muerto» no es futurista, no es un aviso premonitorio, tampoco un deseo proveniente de un ateísmo desenfadado o un desencanto espiritual, sino todo lo contrario, relata un acontecimiento en desarrollo, que ha sucedido antes y que está sucediendo, mientras y después de que se tenga referencia de él. Ya el mar está vacío y el horizonte no existe. Si bien, como la luz de las estrellas más lejanas, el acontecimiento aún está en camino, vivimos mirando al sol del crepúsculo y no al de la aurora.

Las teorías metafísicas tradicionales operaron como sistemas globales referidos a un único principio de lo real y fundamento cosmovisional, cuyo objetivo era establecer una correlación entre «sen» y «pensamiento» donde se privilegia la identidad, la idea y la teoría, respondiendo así a una necesidad ontológica y epistemológica de un principio explicativo último desde el cual explicar las determinaciones del ser y desde el cual fundamentar las cualificaciones de la realidad:

La muerte de Dios ha sido entendida por la modernidad como un progreso, el triunfo de la razón, la posibilidad de construir un mundo a imagen y semejanza del hombre. La secularización aparece como la síntesis superadora del dogmatismo y un paso de gigante hacia un futuro de libertad antes apenas previsto. Para Nietzsche se trata de una sustitución: destitución de la correlación de fuerzas que culminaba en Dios y de la que pendía todo un sistema de valores, de convicciones, de certezas (...), e institución de otro sistema diferente de fuerzas que, en algún caso, no es sino la prolongación inconsciente del anterior. La lectura en clave de progreso, el optimismo moderno, no es otra cosa que la perspectiva del vencedor: el conjunto de fuerzas 'hombre moderno' ha superado al conjunto de fuerzas 'hijo de Dios'. Nietzsche denuncia la conversión de tal victoria en síntesis superadora: el hombre más feo ha matado a Dios; se trata de la crónica de una batalla; manifiesta un estado coyuntural: también el hombre es algo que tiene que ser superado ${ }^{70}$.

69 F. NieTzSCHE: Correspondencia. Trotta, Madrid 2005, "Carta a Elizabet Nietzsche", 11 de junio de 1865, 336-337.

70 P. LANCEROS: La herida trágica: el pensamiento simbólico tras Hölderlin, Nietəsche, Goya y Rilke, 174. 
En fin, la «muerte de Dios», es un acontecimiento que se anida en el mismo cristianismo, en su misma administración sacramental, pero sobre todo, se oculta en su accionar socio-cultural como «Cristiandad», es decir, como paradigma cultural expresivo-estético, psico-espiritual, normativo-ético forjador de una identidad que en la entrada de la época moderna, cae tanto en crisis de modulación práctica como en fragmentación de su estructura racional.

Sumario: Introducción; 1. La grieta abierta por la «muerte de Dios»: el nihilismo como deshumanización; 2. Sentidos de la «muerte de Dios» como metáforas modernas; Palabras finales. 